\title{
Structuring a Philosophical Approach
}

\author{
Richard Startup \\ Honorary Research Fellow, Swansea University, Swansea, UK \\ Email: r.startup@swansea.ac.uk
}

How to cite this paper: Startup, R. (2019). Structuring a Philosophical Approach. Open Journal of Philosophy, 9, 452-469. https://doi.org/10.4236/ojpp.2019.94028

Received: August 12, 2019

Accepted: October 12, 2019

Published: October 15, 2019

Copyright (c) 2019 by author(s) and Scientific Research Publishing Inc. This work is licensed under the Creative Commons Attribution International License (CC BY 4.0).

http://creativecommons.org/licenses/by/4.0/

\begin{abstract}
A framework is developed for understanding what is "taken for granted" both in philosophy and in life generally, which may serve to orient philosophical inquiry and make it more effective. The framework takes in language and its development, as well as mathematics, logic, and the empirical sphere with particular reference to the exigencies of life. It is evaluated through consideration of seven philosophical issues concerned with such topics as solipsism, sense data as the route to knowledge, the possible reduction of geometry to logic, and the existence and status of human rights. Various dichotomies and the notion of continuity are evidently highly strategic.
\end{abstract}

\section{Keywords}

Certainty, Wittgenstein, Scepticism, Language, The "Taken for Granted"

\section{Introduction}

The project of this paper is to delineate a structure for what is "taken for granted" in philosophical inquiry and by making that form explicit thereby further the philosophical enterprise; in this connection, consideration is given to the treatment of seven philosophical issues. As a way into the topic attention may usefully be drawn to two disjunctions: that between philosophical work and how philosophers lead their lives, and that within philosophical inquiry between that which is being examined and that which is taken as given. Consider, for instance, the not unfamiliar point that philosophising can involve seeming inconsistencies or even hypocrisies. In their ordinary lives sceptical philosophers, like others, speak in the vernacular and make the everyday distinctions between the known and the unknown (Baldwin, 2011: p. 553). Wittgenstein made the sharp remark that, "Those philosophers who have denied the existence of Matter have not wished to deny that under my trousers I wear pants" (quoted Wisdom, 1942: p. 431). On a related but different point, it is often remarked in connection with 
philosophical inquiry that while one element is being explored certain other elements are assumed or-at any rate temporarily-being taken as given. In a philosophical context, doubting one item presupposes confidence in others; a project of doubting everything degenerates into a failure convincingly to doubt anything (Wittgenstein, 1969: Paragraph 115). Important logical or conceptual issues are involved, for doubts need to be grounded, with the grounds being constituted by beliefs which are not in doubt (Baldwin, 2011: p. 558).

A further-familiar-way of putting it is to say that the possibility of mistakes and doubts presupposes adherence to a "picture of the world", but Wittgenstein goes further by identifying assertions-even common-sense truisms-as "privileged starting points which we rely on in making sense of our experience" (Baldwin, 2011: p. 558). He introduces a helpful metaphor: "That is to say, the questions that we raise and our doubts depend on the fact that some propositions are exempt from doubt, are as it were hinges on which those turn" (Wittgenstein, 1969: Paragraph 341; Pritchard, 2011: p. 530). In going further he connects some "hinge" propositions to our "natural" dispositions and to our animal nature. His point here is that life is conducted on the basis of practices within which language and behaviour are integrated for the achievement of practical goals which brings in a presumption of certainty; since uncertainty could not lead to action. Perhaps this is going too far because we often proceed on the basis of a combination of hope and expectation, but then, of course, no doubt there would be other matters taken for granted or-temporally at least-taken as given. At least one is alerted to the way in which issues of doubt and certainty "play out" differently in philosophical as against practical contexts. In this connection Wittgenstein has employed the notion of differing language games but that can leave one uneasy because within a "way of life" contexts are not totally divorced and language games connect up: it is not as though one is talking about draughts and chess.

This article is stimulated by these kinds of observations and particularly by the content of Wittgenstein's On Certainty (Shanker, 1986), although-in all honesty-it is pretty certain that it would not find favour with that author, given that its direction of travel is towards "systematising". A jumping off point is provided by the notion of hinge statements and matters "taken for granted" in life generally and in philosophy. Is it possible-one may ask—to delineate a structure for the "given" or "taken for granted"? It is evident, for instance, that in identifiable contexts some considerations are logically prior to others, in which case there may be even greater danger that they are taken as given rather than scrutinised. The most obvious case is that of language itself which, as Bertrand Russell commented, for an extended period he (even he!) rather assumed to be a "neutral" window on the world, thus leaving him open to misapprehensions. Above one implicitly apologised for this article being systematising and a further apology is due: each section of it is abbreviated-short and partial. This is almost inevitable given its very broad scope but brevity may at least have the merit that the direction of travel may become clearer. Picking up on the significance of Russell's 
remark, initial attention is directed at language; consideration is then give to the nature of "what is the case" taking in the empirical, contingent sphere as well as mathematics and logic, with a concentration on the former. The significance is then evaluated of the fact that language originated in time and "evolved", in the sense of developed continuously; then-noting Wittgenstein's (informal) reference to our natural dispositions and animal nature-a further section is concerned with the way in which language is shaped by the exigencies of life. In an attempt to alleviate the pressure of that philosopher's stern gaze there follows a consideration of how various philosophical questions may be treated which it is hoped demonstrates some strengths of a structured approach.

\section{Language}

Language is the ubiquitous element; it is like air seemingly everywhere available and penetrating into the most intimate parts. Language flows, sometimes in tiny rivulets, sometimes in oceanic currents. It is meaningful or at least it often makes sense but sometimes does not. It can even sometimes seem a bit mad but, if this is madness, then "there is method in it". It seems that certain things are "allowed" in it, others not. "Allowed" is doubly pertinent because language is "moody". It is sometimes insistent, even seemingly dictatorial, but also sometimes reassuring; doubt may be felt but may also be dispelled; language may be lyrical but, on the other hand, it sometimes comes across as neutral.

Sometimes things happen, sometimes not; sometimes things may happen, sometimes not. It seems the second of these pairs ("may" and "may not") are not infrequently found together. There is sometimes a sense that things are going on, or more fully, that they have gone on, or are going on or will go on; there is a sense that "going on" is between "have gone on" and "will go on". "Doing" is important in language. Sometimes something is done to something else; sometimes it is done to itself; sometimes it is just done.

Language contains a dramatis personae, including "I", "you", "he", "she", "it"; although one must be alert to the fact that in this drama "I" may sometimes seem quickly to transmute into "you" and vice versa. Two other characters with the same tendency are "this" and "that". There can be a "sense of direction" as "I" does something to "you"; there may also be a sense of direction towards "this" and "that".

The reader will already have concluded that the last three paragraphs are partly intended, in a Brechtian manner, to generate a "distancing effect" from what is highly familiar so that its role may be less "taken for granted" and therefore conceptualised in a more challenging way. Given its significance later on, it is worth particularly picking out the (indexical) use of "I" associated with the personal and the individual, which at first glance takes one away from what is shared, but every aspect of which is governed by linguistic convention; however private or personal a topic, language may probe there. There are other aspects beside the linguistic which may suffer the fate of being taken "as given". 


\section{What Is the Case?}

To proceed further, it behoves one to consider "what is the case"; assertions about this are understood to be true or false. Communication within a community takes many forms, for instance a request for help, an instruction, an order, or a compliment, and is integrated into a way of life. However, given our material existence and interdependence with an environment, of particular importance is language addressed to the conditions of human activity or "what is the case". The relation between language and "what is the case" is what is being analysed in Wittgenstein's Tractatus Logico-Philosophicus. The two main types of assertions to consider are empirical and mathematical propositions: for instance: "there is snow at the Antarctic"; " $2 \times 2=4$ ". In what follows one is somewhat more concerned with the empirical sphere but mathematics and logic must be situated.

In short, logic and mathematics mediate between language and "what is the case", while being able to claim membership of both categories. Conventionally, people are maximally confident or "certain" about mathematical results, but, on the other hand, perusal of mathematical works reveals they consist of a series of sentences and figures. There is point to the familiar remark that "mathematics is a language"; at one level it may be construed as a specialised extension of ordinary language. Hence it may be said to have a dual character i.e. as language and as "what is the case". That logic and mathematics are close is suggested by the observation that mathematics consists of accurate reasoning, i.e. it has logic as its basic underlying element (which in itself would imply, in conventional terms, that logic must be "at least as certain" as mathematics). On the other hand, the previous section was given its Brechtian character partly to point up that logic is integral to basic uses of language, such as the idea that the present is "between" the past and the future, and the way we employ modality.

As Kant and Wittgenstein particularly help to make clear, logic is basic to the conceptualisation of the empirical sphere. It is at the root of key concepts and frameworks employed such as time, space, and causality (Pertinent here are a priori notions, identified by Kant, which though they may be elicited by experience, may be understood to have a basis other than experience; geometry specifically is considered in a section below). With respect to time and distance, the uses of "later than" and "further than" respectively may be characterised as transitive. Logic incorporates a structure of rules (some grammatical in nature) for making meaningful assertions which may be judged true or false. Hard precisely to pin down, in Wittgenstein's judgement logic is not a theory nor reflects the world (Wittgenstein, 1922: 6.13) but its propositions "are tautologies" (Wittgenstein, 1922: 6.12) (see also Black, 1964).

This is pertinent as one proceeds to focus on the empirical sphere. An initial purpose is to clarify that "what is the case" incorporates not just what we consider to be everyday states of affairs but also observation of them; also to draw attention to the point that observers are in a certain sense "replaceable". A selected example concerns there being an electric blanket on a particular bed. 
Suppose someone says: "there is an electric-blanket on my bed but no-one else sees or knows it". That person may be sensitive to their privacy, but it is understood that were anyone else to be placed in the same position they too could see it and know that it is there. Importantly, instances where people gain knowledge through observation or through other senses are themselves understood as situations which are knowable from a general point of view. In principle, all instances of observation or communication about it are themselves knowable.

Following on from this, quite reasonably there is a tendency to equate a "state of affairs" with what is "knowable" but it must be appreciated that the word "know" is used in a variety of ways (Wittgenstein, 1969: Paragraphs 330, 357, 379-380, 424, 483-484; "you can rely on it", Paragraph 561) and here one is concerned with knowing in the limiting sense where one can only be said to know something that is indeed the case. That which is knowable in this way may be referred to as (potentially) a "state of affairs" or fact.

Hence there are innumerable examples where what is the case could be said to be "publicly observable" i.e. anyone could in principle be so placed as to be able to confirm it. Importantly, language also refers to events which are not publicly observable in this way, such as the feeling of pain or occurrence of thoughts or an instance of memory recall. In this connection attention is often drawn to the point that these are hard for other people to verify. Yet, importantly, it is not doubted that someone could be in pain or could be thinking about something; this logically relates to the point that assertions on these matters are treated as potentially true or false. Hence language makes clear that these types of occurrences-sometimes referred to as "subjective states"-are real enough i.e. that someone feeling a pain is potentially as much a fact-or state of affairs-as someone sitting on a bus. So too does language readily embrace phenomena where there is participation of the mental in the physical as with blushing or a smile.

\section{The Continuity of Language}

Now language only evolves gradually-it changes continuously-and to understand its role it pays to take account of origins and antecedents. Humans evolved from other primates and one can speculate about aspects of the origins of language, but do so responsibly. Although we now know about an immense universe, the origins of language would lie in the perspectives of the kinship groups of preliterate peoples. Very roughly there must have been a passage from an animal world of sensation (where sensations are "private") through to a human grasp through language that existence is in "a world of objects" (where objects are "public"). To assist understanding of this transition in more biologically-or social psychologically-oriented terms, reference is made to a human capacity to operate with "theory of mind" or to "take the role of the other", but in the present context it is pertinent to say that what is involved is people coming, for instance, to understand that they are viewing the same thing from the same 
place. This understanding arises because, unlike animals, they are, through language, able at least implicitly but sometimes explicitly to "compare notes" on experience. The world of objects is, besides language, the other main system the existence of which or form of which is taken for granted within certain types of philosophical discussion.

The world of objects-the physical world-roughly speaking consists of the two overlapping classes of things we can use-potential resources-but also obstacles or things we "come up against". Human bodies are numbered among the physical objects. Indeed they are to be construed as an essential feature, a foundational element of the physical world. This is to do with the fact that they necessarily have the same object status as things with which they are in contact or "touch". From the outset bodily differentiation is the primary way we are individuated as people. As regards the non-human aspect of the world it may follow from our evolutionary background that there is also early conceptualisation of animals as individual gestalts (rather than their individuality needing to be an integration of elements as in the way we understand a complex building); after all, they can be our food source and vice versa.

As people are differentiated, actions may be attributed to them including linguistic actions (analysable as distinguishable speech acts; Searle, 1969 and 2010); the source has physical location. There can also be cooperative sources. Many uses of speech are publicly observable. It is also the case, however, that it becomes possible to attribute private uses of language to people as their thoughts. There can be soliloquy which is in principle publicly observable but also mental activity which is not. Importantly, thoughts or memories, some of which are rendered in propositional form, do not have an intrinsic location, although the content of thought could include locational aspects. Their status as "his or her thoughts" conceptually links to individuality and is secured by the shared understanding that a person has physical location.

Importantly too we do not just touch things but also lift them which is probably foundational in relation to the idea that an object has weight. There would be early grasp of the fact that a woman could lift her young child but not vice versa. Objects are things which cannot always be crammed into the same place but they may be able readily to occupy it successively-hence there is a source for a developing conception of space. It is the conception of space that is foundational in respect of geometry. From the earliest stage too there is experience of change within which context objects persist; so the conceptualisation of objects in their context is bound up with an incipient conceptualisation of time. The differentiation of objects would also be foundational in respect of counting and the conception of number.

Plainly the last few paragraphs are indeed speculative but they are offered not as a definitive account but as pointing towards the kinds of considerations which bear upon the character of language. It is of the essence that language only develops continuously: that which goes before is the only basis available for increments and innovations. It may well be the case that language could have taken 
other directions but they are not as it were on offer to us today. We are familiar enough with the way individual languages develop slowly and continuously; so do the associated systems of ideas.

\section{Exigency}

Following on from a consideration of origins and basics, it is essential to take full account of the fact that, developing language usage-from the earliest stages through to the present-is shaped by the exigencies of life. One need hardly say that life sometimes takes the form of a desperate struggle. Language gets many of its basic senses and uses from a context of practical need rather than one of calm reflection. A basic point is that humans need to cooperate in order to survive-to gain access to the means of their own subsistence. The following remarks are again intended to be strategic but suggestive rather than exhaustive. A key idea is that we need to rely on one another. In short, people need to rely on circumstance and availability of means-especially in the form of other people.

Plainly consideration of circumstance points to the use of the idea of truth or falsity. There are differing uses of language but where we rely on the understanding of a straightforward indicative assertion we are more likely to achieve our objectives should it prove to be true. The notion of promising or giving an assurance points rather in the same direction. Above reference was made to the use of the word "know". Where people say they "know or know for sure", it often smacks of giving an assurance, rather than simply offering a veridical record. In a basic way interrogative uses of language make it clear that sometimes something is being sought-and it may be urgent. Vocative and imperative uses of language are often geared to bringing about a desired state of affairs.

Proceeding further, there are a set of locutions which bear upon issues, well known for their treatment by Hume, to do with induction and cause and effect. In practice human beings will often, with varying degrees of confidence, "repeat the dose". For instance, one may return to a place to pick blackberries this year where many were to be found last year. Hence action is often governed by hope combined with expectation. We actually base our lives on all manner of ad hoc inductions no one of which would be "watertight" in a Humean sense, including that the Sun will rise tomorrow (although it should be added that in a modern context that particular expectation is made more secure by scientific theory).

The notions of cause and effect are pretty basic in actual life, whatever problems they raise philosophically. Reverting to speculative anthropology, a possible source lies in the human ability to "produce" outcomes: as when an arrow is fired and a deer drops dead, an example which rather prompts immediate use of our word "because", although the thought may be unspoken. Important too are ideas to do with purpose. Again, whether or not somebody may properly be said to have a particular purpose is part of the factual context. The way in which purpose is important is in predicting or foreshadowing behaviour. Most obviously if the other person seeks to be helpful that will likely prove more useful in one achieving one's objective than if he or she has ulterior motives. The word 
"motive" just used is part of an elaborate vocabulary connected to the idea of purpose. Notions of cause and effect together with that of purpose relate also to the idea of "blame". We blame or shame people partly so as to shape their future behaviour.

In this type of account certain "traps" are to be avoided. It is absolutely not the case that the world in the sense used here is to be construed as "whatever human beings say it is". Readily available in ordinary language usage is the distinction between "what everybody believes" and "what is the case" and, yes, it may indeed be the case that the Earth is a sphere/geoid although everyone believes it to be flat. Also seductive is the suggestion that humans "interpret" the world in a variety of ways, so-it might be suggested-these interpretations warrant inclusion on the same basis as objects answering to more mundane descriptions. What, for instance, about an animal or rock considered a god? Does the world now include cats, dogs and gods? The reply must be that people are free to interpret in all manner of ways, but one is concerned here with the constituents of a world of objects. Another way of putting it is that the human body is a foundational part of the latter world and other elements of that world have the same existential status as it does.

This links to the fundamental conceptual point that the physical world varies continuously: a related way of putting it is to say that a physical object could conceivably occupy any position in it. (This particular conception is modified in modern physics.) One may briefly situate other phenomena. No, a rainbow is not a physical object, but its location is with respect to an observer. With regard to the sea, its position/direction may be given by reference to objects; water also competes with objects for space and takes some lifting. With regard to the sun, moon and so on, $a b$ initio these might have a status somewhat similar to, but less ephemeral than, the rainbow. However, bearing in mind the key point regarding continuous variation, on the basis of observation of terrestrial objects combined with observation of the heavens (particularly crucial at an early stage being naked-eye observation of the moon's phases and of eclipses) what might simply have been viewed as "lights in the sky" is conceptualised as physical objects. It is highly indicative that the advance of science has had the largest single impact on our modern linguistic resources: according to the linguist David Crystal it may be judged that over half the words in the English language are scientific terms.

Importantly, the resources of our language equip us to understand fully that other people may deceive in word and action. A person may tell the truth or lie; a person may do something or pretend to do it. Human beings are able to act (as on the stage); we can all do this at least to a rudimentary extent. A way of putting this is to say that for every primary way of behaving there is a secondary way. We can indicate the intention to do something while not intending to do it. What is evident is that the secondary way of acting only exists because of the primary one; it is parasitical upon it.

In proceeding further an objective is to evaluate the usefulness of the frame- 
work presented. It may be that it can make the treatment of particular philosophical issues more systematic or succinct. The way it is set up assigns a central position to language, within which context one may distinguish differing language styles in practical and reflective contexts, but there is no reason to expect that these are sharply demarcated. The framework may serve to sensitise one to the importance of particular concepts or dichotomies; even the relations of differing "language games". The hope is that it may contribute to structuring a philosophical approach. The extent to which it may do so should become clearer from consideration of selected examples of philosophical issues.

\section{Philosophical Issues}

\subsection{Do Other People Really Feel Pain?}

It is being asked what reason is there for believing that other people feel pain as opposed merely to expressing it by such behaviour as wincing or through report. Crucially, it may be said that the reality of feeling pain (as opposed to its manifestations) is reflected in ordinary language usage which usage pre-dates any putative instances of pain under consideration. Furthermore, one may make the following observations in one's own case. My own experience of pain and its various manifestations accords with ordinary language usage. For instance, I personally feel minor pain occasionally which may or may not be expressed publicly; I have also felt major pain in ways apparent to onlookers. In sum, my experience accords with ordinary English usage; therefore I have no inclination to challenge it. So apparently is this the case for virtually everyone else. Hence no challenge is mounted to ordinary linguistic usage, which will therefore continue to be employed.

There are of course also rare instances of people who do not feel pain at all but the fact that that condition can be identified and described demonstrates the value of the way ordinary language is deployed rather than serving to undermine it. Put sharply, those who do feel pain and those who do not may be distinguished. We all also know we can dissemble-pretend to be in pain: that possibility too is acknowledged in language. From this example it is apparent that it is language usage which has primacy-in giving definition to an "internal" phenomenon which may or may not have manifestations. Importantly, instances of that internal phenomenon are not "in need of external criteria" to be said to exist.

\subsection{Are There "Other Minds"?}

Philosophical discussion occasionally gets things "the wrong way up". In the consideration of how we know about "other minds" it sometimes seems as though, from a position of existential "loneliness", one is (rather desperately!) trying to "infer" that others also have a mental life, feel pain and so on. Against this, the "direction of travel" should be from what is shared through to the understanding of individual experience. Using shared linguistic resources one comes to 
understand what it means for others to have their own mental lives, while understanding one has one oneself. Again, experience does not lead to a challenge being mounted to ordinary linguistic usage.

The fact that a single word "mind" is used rather invites the suggestion that some level there is integration, but one must identify the level. True, there are instances of pains, thoughts, and memory recall, but are these integrated into a whole? Certainly there are links. For instance, one can have the thought that earlier one had a pain, but other thoughts may not connect to it at all. Thinking is understood to occupy time and thoughts to be distributed in time; there can be "reference back"; there can be repetitive, even obsessive patterns; but this merely establishes links. We also understand that people can do mental arithmetic as well as deliberate on a topic; these activities take rather more time. In and of themselves the various subjective elements are not tightly integrated into a whole. On the other hand, a pain is often felt to be located-as with toothache-which points more towards the significance of bodily form.

In the quest for something resembling "subjective" integration, typically a lot of weight is put on memory-which is plainly absolutely vital in the survival of the organism. The content of memory is prima facie evidence of something-to oneself directly and to others as communicated; but it is not self-validating: validation has more to do with processes that are public. To illustrate the kind of role memory plays, perhaps I may be forgiven for being personal. I have memories of such remarks as, "Is it raining up there?" On the other hand, it is common knowledge in my circle that I am indeed a very tall person. That is the kind of way subjective memory recall and external reality connect up. Essentially there is integration centred on the wider concept of a person; with persons differentiated by their bodies. The concept of a person entails that "my mind" gains something by way of location through its association with "my body"; both are understood by me in the same way as they are understood by anyone else, but with the difference that I know more in detail about the subjective side-which point is readily understood by all.

Discussion not infrequently gets muddled because people confuse mental events with other "psychological-sounding" aspects of people such as their attitudes and beliefs. A belief is not to be construed as a mental event although it may be expressed in a thought; significantly, that someone believes something persists in extended time in a way that thoughts as such do not. The point is that fundamental to the idea of belief is action tendency (A woman believes Brexit is a bad idea: she challenges others and argues with the television). Associated with this, there are seeming oddities in our use of the idea. If my wife hands me a cup of tea and I start drinking from it, it could be said of me that "I believe that the cup is not poisoned", yet the notion that "this cup of tea is not poisoned" may never have "entered my head" at all. As indicated earlier, there is no intention here to give exhaustive treatment of a large topic (see Ryle, 2009; Strawson, 1974). 


\subsection{Do I Alone Exist?}

Some of the foregoing discussion goes over but more can be said about the use of "I". As stressed above the use of that word is conventional i.e. defined within a language community. Pedantically, one could say I am a "ratified I-user" but so are there necessarily other ratified "I-users". From a linguistic point of view all are equally situated. As above, the contents of my mental life have no intrinsic location, although their content is likely to be differentially concerned with what is understood to be "me", meaning an identifiable person; for many purposes recall is important as evidence. The ratification of me as an "I-user" is logically on all fours with the ratification of the other "I-users". On the other hand, it is shared language and understanding of the world which would enable me to identify the-rather special-state of affairs (perhaps following a nuclear holocaust) where I was the last man/woman standing.

\subsection{Is Our Knowledge of the World Acquired via Sense Data?}

The perspective developed here bears upon the adequacy of the "sense data" notion deployed in some empiricist accounts. There may be an attempt to understand how an (again lonely seeming!) individual acquires knowledge of "the external world" via "sense data". Again, this is getting things the "wrong way up". Knowledge has that status in relation to the wider language-using community. With the exception of subjective states, no-one is prevented by the general conditions of inquiry from gaining the increment of knowledge for himself/herself (In modern conditions this may involve use of an instrument). There is shared understanding of our world. However, crucially, the one thing we cannot do collectively is touch it, see it, hear it, smell it, taste it. Furthermore, we are understood to be, as individuals, seeing, touching and hearing not "sense data" but food, music, a cat and so on. Increments in knowledge are initially acquired through individual observation; if necessary, people then "compare notes".

The "sense data theory" is often launched on the basis of the assertion that we can sometimes be deceived. Crucially, however, that state of affairs and how it might be tackled are themselves treated in language. With regard to the "bent stick" in a glass of water, we say: 1) that we are seeing a stick and 2) that it seems bent or broken, but, nevertheless, is not bent or broken. This last is confirmed by touching and holding it. As stressed here, and against some empiricist accounts, touching rather than seeing is fundamental, although the evidence of the two senses connects up-most particularly in the respect that when two things touch the touching may simultaneously be observed. In addition, there is the understanding that the only route to additional information regarding the physical world is through the observations of individuals, who are substantially interchangeable.

\subsection{Can There Be a Private Language?}

As is customary one may proceed to consider a "Crusoe-like" situation. Suppose 
a man of average bodily appearance, but unfamiliar dress, arrives on his own, in a space-ship from outer space. He tries to communicate orally but, not surprisingly, without much success, but he is compliant and allows himself to be installed in a conventional domestic setting with his own bedroom. In that setting he is even overheard seemingly "talking to himself". He quickly learns to negotiate the rooms of the house, attend meals, and so on. Furthermore he begins to grasp certain English words-such as "breakfast"-and seemingly utters sounds taken to be corresponding words in his own language; he builds towards uttering very short remarks in English. What may perhaps be said is that this man is a "candidate" for being someone with his own private language: after all, he may reasonably be thought to have a language and "think" in that language; he is also the sole known user of the language.

Of course, for very good reasons, everyone responds by asking such questions as: What is his origin, his community; how did he acquire his language; what about his memory of his past life; how come he even tries to speak to us? Were almost any of these questions to be answered substantively his "candidacy" would immediately collapse. Nevertheless, ahead of that happening, a straight-batted response is to say: But those are other questions and who knows what the answers may be; after all, he comes from outer space. Were question and answer to be "left there" there is a certain similarity to the following exchange within a different context: How is God able to communicate with people in English? Answer: Who knows? (God's linguistic capacities do not, it seems, derive from participation in a conventional language community).

Language (like morality and the law) purchases on actual human experience. It also accretes to handle what are judged to be fundamentally new phenomena, such as technological innovations. Like morality and law, language usage may be characterised as "conservative" in that it tries to preserve existing practice where it can, which would be likely to apply here. In the absence of any real context for this man's capacities, instead of talking about his private language, it might be said that, on his arrival, he lacked "true language" but has "self-linguistic tendencies" of a previously unknown kind (This could even lead in the direction of saying that "he is not really a man"). In sum, there is very unlikely to be acceptance within the language community that it is appropriate to talk about someone having a private language.

\subsection{Geometry, Topology and Logic}

Arising out of the framework developed here the aim is to make a strategic (if esoteric) point concerning the relation between geometry and logic. The aim of Whitehead and Russell's Principia Mathematica was to show that in some significant sense mathematics is reducible to logic. To that end a substantial specialised set of symbols was developed and put to use in its many definitions and theorems. The authors were only partially successful although their system proved able to handle number and elementary arithmetic. The question arises: could such a reduction of geometry be effected? The fact that Euclidean geometry is axi- 
omatised rather points in that direction (the system many of us are familiar with from school mathematics is a reworking of Euclid by the French mathematician Legendre in the nineteenth century). Significant too is the point that number may be interpreted geometrically and geometry is integrated with arithmetic and algebra in analytical geometry. Hence there are some signs pointing towards a representation of geometry in purely logical terms. The suggestion being made here, however, is that such a reduction would be likely to founder.

It will be recalled that Euclidean geometry takes in both plane and solid geometry; in addition, there is no problem in respect of the algebraic representation of figures of any dimension (including, for instance, the four dimensions of relativity). In both cases, however, the notion of dimensionality is taken as "a given". In the twentieth century a more precise definition of the concept of dimensionality was forthcoming and it was also noted that an inductive definition of dimensionality is implicitly contained in Euclid's Elements; that led on to the development of an extensive theory of dimension (Courant \& Robbins, 1958: pp. 248-251). This important mathematical work in itself, however, does not point to the analysis of dimension in purely logical terms. In this connection, it may be that mathematical induction is not itself reducible to logic in this sense, whence its designation as "a principle". Indeed it is critical that language may not assist in this project since, although it lends itself both to differentiation of objects in the world and of linguistic items (such as words) which may contribute to a reduction of number to logic, it offers no comparable resources which could effect a reduction of dimension to logic. The notion one is rather left with, therefore, is that dimensionality has its primary source in the facticity of the physical world, encountered as "a world of objects". The deeper implication may be that the conditions for a limited reduction to logic as was partially effected for number and arithmetic are lacking.

\subsection{Are There Human Rights?}

In the modern era it would be taken as a "given" that people have rights: one is again in the realm of the "taken for granted". Consider the question: "Do individuals have arms, legs, rights and responsibilities?" This could be answered summarily in the affirmative, but most would sense that something odd is going on; an unease which connects to the idea of a "category mistake". To sort this out attention needs to be directed at language and exigencies.

When one reflects on it, it can seem a minor-or even a major-"miracle" that humans now live together in their billions on this planet, without there breaking out a "war of all against all"- to evoke the Hobbesian scarecrow image. We all have our individual aims in life-and often act without even knowing other's aims-so it seems we are bound to collide. The explanation of course is the institutionalisation of rules in the form of the law, morality, even rules of good manners. Very importantly, two distinguishable elements are involved, with links to the earlier distinction between the public and the private. On the one hand, there are agencies of social control in the conditions/circumstances of 
action of all of us, such as the police and law courts. That alone would never be enough to produce relative orderliness. The other element is that individual people themselves have been changed, so that they may be said to have "internalised" rules and norms: an individual person may understand and contemplate a rule and also adhere to it. Some aspects of social control are public but others are mediated through subjective experience.

That the paramount need is to maintain order is fundamental. As a consequence the language of rights and morality has to an extent assimilated itself into the language concerning "what is the case"; whence the similar form of "humans have arms and legs" and "humans have rights and responsibilities". Jeremy Bentham challenged the idea saying, "natural rights is simply nonsense...nonsense upon stilts". He objected to the way that in the context of the French Revolution the notion of rights, "assumes its substantive shape, and joining itself to a band of suitable associates, sets up the banner of insurrection, anarchy, and lawless violence" (quoted in a similar context by Blackburn, 2009: p. 178). At least it will be agreed that the French Revolution was a time of "exigency". Bentham understood the notion of rhetoric and sensed that he was confronted by something being fast endowed with "object-like" qualities.

\section{Some Key Points Arising}

The first three philosophical issues are conceptually linked. I can only come to identify that I am in pain, or have a mind or am a person, using linguistic resources shared within the community. One only comes to identify the state of being in pain in oneself while recognising that the same may hold for other people; one only comes to view oneself as having thoughts and a mind while coming to attribute these aspects to other people. Hence the primary notion is that of a person of which I am one. As indicated earlier, we are individuated as people within the world of objects.

In respect of the sense data theory of our knowledge of the world, it is unclear how sense data deriving from differing senses, e.g. "seeing sense data" and "touching sense data", could be integrated simply from their intrinsic nature; nor is it clear how any such data could yield what is to be understood as knowledge without confirmation by reference to more than one human subject. Once one understands human beings as belonging to a world of objects, the sense organs are identified and their joint operation understood. The sense data theory can only even be approximately understood while the world of objects is taken for granted. The only way to unravel the confusion in the first four philosophical issues is to focus explicitly on that world.

The fifth issue above, concerning a private language, hinges on our reluctance to classify any linguistic-seeming phenomenon which lacks a social-communicative character as language. Hence it draws attention to the continuity of linguistic practice within a community, which implies in-built conservatism (cf Occam's Razor, the principle that entities are not to be multiplied beyond necessity). Hence the crux of the issue is the continuity of language. 
To draw out the significance of the sixth philosophical issue treated above, one may note in passing, but not be unduly distracted by, a particularly straightforward point. Of course it is the case that geometry has its historical roots in mensuration, but the philosophical treatment considered here has a different focus. The point is that that treatment seems to be firmly of a logical/mathematical type, but, if the account given here has validity, the issue concerning dimensionality cannot be detached from the given nature of the "world of objects".

The final philosophical issue belongs to moral philosophy and emphatically concerns the exigencies of life. The language of human rights contributes to the avoidance of a Hobbesian war of all against all. A rhetorical purpose is served by endowing rights with "object-like" qualities. Linguistically, rights are being presented as sharing in the unchallengeable-and taken for granted-reality of objects in the world. Hence, philosophical clarification is needed of the impact of exigency on the continuity of language.

\section{Conclusion}

The earlier sections of this article successively focus firstly on language, then on "what is the case" including logic, mathematics and the empirical sphere; then on the continuity of language including the understanding that we inhabit a world of objects, and, finally, the exigencies which shape life and language. The value of a systematic treatment is evident from consideration of the seven philosophical issues. The first four issues are appropriately sorted out by analysis of "what is the case" in terms of a physical world with human beings in it; in a narrower way this even arises in respect of the issue concerning dimensionality in geometry. Consideration of the topic of a private language draws attention to the need to focus on the continuity of language. Finally, the topic from moral philosophy requires analysis of the impact of exigency on the continuity of language. In an identifiable sense progress may be made in each case by making the explicit focus aspects which were previously implicit or taken for granted.

The project of this paper to delineate a structure for the "taken for granted" and to illustrate its usefulness has thus to a degree been realised, but it is partial in two respects. The first way in which it is partial is that the types of philosophical issues used as illustrations are somewhat of a kind; they tend to be (sometimes relatively well-worn) topics raised within what may be characterised as the logical empiricist tradition. I have tried to select for "band-width"-including, for instance, moral philosophy and a mathematical/logical issue-but the net has not been spread that widely. The second is that one may be left wondering just how much of the earlier detail is actually used in tackling the issues. Perhaps the most that may be claimed is that the approach makes the treatment of disparate philosophical topics more systematic; it also serves to orient thinking, even function as an aide memoire, which may be an indication of promise.

One is also sensitised to the "grammar" involved as various dichotomies are deployed such as those between the subjective and objective and between the 
public and private. So too, is one's attention directed at indexical uses of language especially the use of "I", on the one hand, and impersonal uses on the other. Importantly, one is led strategically to deploy the notion of continuity in two very different contexts: spatial occupancy and linguistic development. These distinctions alone imply a structuring of inquiry with language assigned primacy.

A further important dichotomy is basic to empiricism and concerns, on the one hand, the empirical, contingent or putative "external world" and, on the other, human observation (in the broadest sense) leading to knowledge of it. Importantly, what is observed and the occurrence of acts of observation are equally publicly accessible. In this connection, however, the idea of one observation "confirming" another so that we thereby gain knowledge of "what is the case" is crucial. The point is that linguistic communication is fundamental to any confirmatory process. It is of the essence, that all communication among humans has the same kind of public facticity as does the subject about which they are communicating. It is sometimes commented that communication is "meaningful" as though this complicates matters essentially. The response is to say that it can be as meaningful as you like but it is nevertheless physically mediated e.g. conversation is mediated through sound waves passing through the atmosphere. The public nature of process at all stages relates logically to the public nature of the product.

At more than one point in this account an important part has been played by the distinction between primary and secondary phenomena. Thus humans can do or feel innumerable things but also pretend to do or feel them; they can, as we say, lie in word or action. Seemingly, direct observation presents the "illusion" of a straight stick becoming bent in water, but further observations confirm that the stick has not become bent. In a rather different way humans may be judged to be pretty "uncertain" of almost everything but a second-order certainty is that they rely on knowing many things in conventional terms. Once there is understanding of how ordinary language negotiates its way round the primary and secondary "landscape" - which it does without pausing for breath-the associated philosophical problems tend to "dissolve"; probably meeting with Wittgenstein's approval.

Language games are distinct-until they are not distinct. It would be a commonplace observation to say that the language of rhetoric "works in quite different ways" from that of science; that is until there is reference to both "natural rights" and the "natural world". Morality, the law and politics have, as it were, "called in aid" language directed at "what is the case". The underlying reason is the paramount need to legitimate certain ways of acting; so as powerfully to assist orderly goal achievement in a context of exigencies. While participating in a sociological study of the church I heard a member of the laity say, "God is not lonely, he has angels for company". This has the same form as, "I am not lonely, I have my wife for company". There is evidently a need for a second-order study of how differing language games "borrow" participants and pieces in play. 
Shortly above is a section concerned with arguing that the kind of reduction of elements of mathematics to logic effected by Whitehead and Russell may not be possible for the key geometrical notion of dimension. Following on from this, the broader question is raised: how is the division in mathematics to be made between those parts susceptible of reduction to logic and those not so susceptible? If there is such a demarcation, how is it to be accounted for? One is drawn to this line of inquiry but, this time, it would probably not attract Wittgenstein's approval.

It must be acknowledged that at the end of the day the overall thrust of this account is in a certain sense realist. It is hoped that it has taken to heart at least one or two significant points from both Wittgenstein's earlier and later philosophies (Wittgenstein, 1997); that it draws both from his insights on the logical structure of propositions while doing more than curtsying towards scrutiny of everyday uses of language. A further dichotomy is between practical activity geared to survival and reflection on it. Reflection must be deeply informed by an understanding of practical activity, while recognising that their linguistic components are integrated within a single linguistic universe.

\section{Conflicts of Interest}

The author declares no conflicts of interest regarding the publication of this paper.

\section{References}

Baldwin, T. (2011). Wittgenstein and Moore. In O. Kuusela, \& M. McGinn (Eds.), The Oxford Handbook of Wittgenstein. Oxford: Oxford University Press.

Black, M. (1964). A Companion to Wittgenstein's Tractatus. Cambridge: Cambridge University Press.

Blackburn, S. (2009). The Big Questions: Philosophy. London: Quercus.

Courant, R., \& Robbins, H. (1958). What Is Mathematics? London: Oxford University Press.

Pritchard, D. (2011). Wittgenstein on Scepticism. In O. Kuusela, \& M. McGinn (Eds.), The Oxford Handbook of Wittgenstein. Oxford: Oxford University Press.

Ryle, G. (2009). The Concept of Mind: $60^{\text {th }}$ Anniversary Edition. London: Routledge. https://doi.org/10.4324/9780203875858

Searle, J. R. (1969) Speech Acts: An Essay in the Philosophy of Language. Cambridge: Cambridge University Press. https://doi.org/10.1017/CBO9781139173438

Searle, J. R. (2010). Making the Social World: The Structure of Human Civilization. Oxford: Oxford University Press.

Shanker, S. (1986). From Philosophical Investigations to On Certainty. In Ludwig Wittgenstein, Critical Assessments. London: Croom Helm.

Strawson, P. (1974). Individuals: An Essay in Descriptive Metaphysics. London: Methuen.

Wisdom, J. (1942). Moore's Technique. In P. A. Schlipp (Ed.), The Philosophy of G. E. Moore. La Salle, IL: Open Court.

Wittgenstein, L. (1922). Tractatus Logico-Philosophicus. London: Routledge \& Kegan Paul. 
Wittgenstein, L. (1969). On Certainty. Oxford: Blackwell.

Wittgenstein, L. (1997). Philosophical Investigations (2nd ed.). G. E. M., Anscombe \& R. Rhees (Eds.), Oxford: Blackwell. 